\title{
Globus pallidal deep brain stimulation for Tourette syndrome: Effects on cognitive function
}

Davide Cappon, $\mathrm{PhD},{ }^{1,2+}$ Mazda Beigi, $\mathrm{PhD},{ }^{1+}$ Zinovia Kefalopoulou, $\mathrm{PhD},{ }^{1,3}$ Ludvic Zrinzo, $\mathrm{PhD}^{1}$ Joseph Candelario, BSc ${ }^{1}$ Catherine Milabo, BSc${ }^{1}$ Harith Akram, $\mathrm{PhD}^{1}$ Viswas Dayal, $\mathrm{MD}^{1}$ Jonathan Hyam, MD, ${ }^{1}$ Lewis Kass-Iliyya, MD, ${ }^{4}$ Monty Silverdale, $\mathrm{MD}^{4}$ Julian Evans, $\mathrm{MD}^{4}$ Patricia Limousin, $\mathrm{PhD}^{1}$ Marwan Hariz, $\mathrm{PhD},{ }^{1,5}$ Eileen Joyce, $\mathrm{PhD}^{1}$ Thomas Foltynie, $\mathrm{PhD}^{1}$ Marjan Jahanshahi, $\mathrm{PhD}^{1,6 *}$.

${ }^{1}$ Unit of Functional Neurosurgery, Department of Clinical and Movement Neurosciences, UCL Queen Square Institute of Neurology,National Hospital for Neurology and Neurosurgery, London, UK

${ }^{2}$ Current address: Berenson-Allen Center for Noninvasive Brain Stimulation, Division of Cognitive Neurology, Beth Israel Deaconess Medical Center, Harvard Medical School, Boston, MA, USA

${ }^{3}$ Department of Neurology, Patras University Hospital, Patras, Greece, 26504

${ }^{4}$ Department of Neurology and Neurosurgery, Salford Royal NHS Foundation Trust, Manchester Academic Health Science Centre, University of Manchester, United Kingdom

${ }^{5}$ Department of Clinical Neuroscience, Umea University, Sweden.

${ }^{6}$ The Clinical Hospital of Chengdu Brain Science Institute, MOE Key Lab for Neuroinformation, University of Electronic Science and Technology of China, Chengdu, China

+ joint first authors

* correspondence addressed to:

Prof. M Jahanshahi, Unit of Functional Neurosurgery, Sobell Department of Motor Neuroscience and Movement Disorders, UCL Queen Square Institute of Neurology, 33 Queen Square, London WC1N 3BG, UK. Email: m.jahanshahi@ucl.ac.uk

Relevant conflicts of interests/financial disclosures: Nothing to declare. 


\begin{abstract}
Introduction: In a double-blind randomized crossover trial, we previously established that bilateral deep brain stimulation of the anteromedial globus pallidus internus (GPiam-DBS) is effective in significantly reducing tic severity in patients with refractory Tourette syndrome (TS). Here, we report the effects of bilateral GPiam-DBS on cognitive function in 11 of the 13 patients who had participated in our double-blind cross-over trial of GPi-DBS.
\end{abstract}

Methods: Patients were assessed at baseline (4 weeks prior to surgery) and at the end of each of the three-month blinded periods, with stimulation either ON or OFF. The patients were evaluated on tests of memory (California Verbal Learning Test-II (CVLT-II); Corsi blocks; Short Recognition Memory for Faces), executive function (D-KEFS Stroop color-word interference, verbal fluency, Trail-making test, Hayling Sentence Completion test), and attention (Paced Auditory Serial Addition Test, Numbers and Letters Test).

Results: GPiam-DBS did not produce any significant change in global cognition. Relative to preoperative baseline assessment verbal episodic memory on the CVLT-II and set-shifting on the Trail-making Test were improved with DBS OFF. Performance on the cognitive tests were not different with DBS ON versus DBS OFF. GPiam-DBS did not alter aspects of cognition that are impaired in TS such as inhibition on the Stroop interference task or the Hayling Sentence Completion test.

Conclusions: This study extends previous findings providing data showing that GPiam-DBS does not adversely affect cognitive domains such as memory, executive function, verbal fluency, attention, psychomotor speed, and information processing. These results indicate that GPiam-DBS does not produce any cognitive deficits in TS. 


\section{Introduction:}

Tourette syndrome (TS) is a neurodevelopmental disorder characterized by the presence of motor and vocal tics starting before the age of 18, lasting longer than one year, with the exclusion of other conditions [1]. Tics are often preceded by an impulse to move, called "premonitory urge" and a sense of relief after performing the tics. TS is associated with poor impulse control, obsessive-compulsive disorder (OCD), attention-deficit hyperactivity disorder (ADHD), and other comorbidities [2]. TS has a major negative impact on the patient's and carer's quality of life [3]. Dysfunction of the cortico-basal ganglia circuits and abnormal distribution of inhibitory interneurons in the basal ganglia have been implicated in the pathophysiology of TS, more specifically tics are considered to be generated through repeated inappropriate activation of striatal neurons, leading to inhibition of the GPi and SNr (which would normally be tonically active to prevent unwanted movements) and subsequent disinhibition of the thalamo-cortical targets [4], [5]. However, there is still debate about characterizing the complex manifestations of tics and the underlying pathophysiology [6]. Current treatments include behavioural therapies such as habit reversal and cognitive behavior therapy in combination with pharmacological therapy. Behavioural and pharmacological treatments can control TS symptoms but 10-20\% of patients prove to be medically untreatable or experience intolerable side effects from the medication [7].

For patients that do not respond to standard behavioural and pharmacological treatments, surgical interventions, such as deep brain stimulation (DBS), is considered a therapeutic option [8], [9]. Since the late 1990s DBS surgery for severe TS had been performed primarily targeting the medial part of the thalamus [10] or the nucleus accumbens (NAc) [11], and more recently the anteromedial part of the GPi (GPiam) [12], [13].

The aim of this study was to evaluate the effect of GPiam-DBS on cognitive function in most of the patients with TS included in the double-blind cross-over trial of Kefaloupolou and colleagues (2015). 
Table 1: A) Baseline clinical characteristics of the study population. B) Comorbidities and medication. C) Randomization order and DBS parameters. YGTSS = Yale Global Tic Severity Scale, Imp. = Impairment scale. Comorbidities: BPD = bipolar personality disorder, GAD = generalized anxiety disorder, $\mathrm{OCD}=$ obsessive compulsive disorder, $\mathrm{OCB}=$ obsessive compulsive behavior, $\mathrm{DEP}=$ depression, $\mathrm{NIL}=$ no comorbidities.

\begin{tabular}{|c|c|c|c|c|c|c|c|}
\hline ID & Gender & $\begin{array}{l}\text { Age } \\
\text { Onset }\end{array}$ & $\begin{array}{c}\text { Age } \\
\text { Surgery }\end{array}$ & $\begin{array}{c}\text { YGTSS } \\
\text { Total }\end{array}$ & $\begin{array}{l}\text { YGTSS } \\
\text { Motor }\end{array}$ & $\begin{array}{c}\text { YGTSS } \\
\text { Vocal }\end{array}$ & $\begin{array}{l}\text { YGTSS } \\
\text { Imp. }\end{array}$ \\
\hline 1 & M & 11 & 33 & 74 & 19 & 15 & 40 \\
\hline 2 & M & 7 & 24 & 81 & 21 & 20 & 40 \\
\hline 3 & M & 5 & 26 & 93 & 22 & 21 & 50 \\
\hline 4 & M & 7 & 25 & 80 & 21 & 19 & 40 \\
\hline 5 & $\mathrm{~F}$ & 12 & 59 & 93 & 23 & 20 & 50 \\
\hline 6 & M & 7 & 49 & 71 & 20 & 11 & 40 \\
\hline 7 & M & 2 & 29 & 96 & 24 & 22 & 50 \\
\hline 8 & M & 6 & 39 & 92 & 21 & 21 & 50 \\
\hline 9 & M & 6 & 43 & 80 & 20 & 20 & 40 \\
\hline 10 & $\mathrm{~F}$ & 3 & 25 & 99 & 25 & 24 & 50 \\
\hline 11 & M & 7 & 25 & 98 & 25 & 23 & 50 \\
\hline
\end{tabular}

\begin{tabular}{|c|c|c|c|c|}
\hline ID & Comorbidity & \multicolumn{3}{|c|}{ Pharmacological Medications } \\
\hline 1 & $\mathrm{OCD}, \mathrm{GAD}$ & \multicolumn{3}{|c|}{ Fluoxetine $20 \mathrm{mg}$, Diazepam $5 \mathrm{mg}$} \\
\hline 2 & $\mathrm{GAD}$ & \multicolumn{3}{|c|}{ NIL } \\
\hline 3 & OCB, Depression & \multicolumn{3}{|c|}{ Fluoxetine $20 \mathrm{mg}$} \\
\hline 4 & OCB & \multicolumn{3}{|c|}{ NIL } \\
\hline 5 & Depression & \multicolumn{3}{|c|}{$\begin{array}{l}\text { Amitriptyline } 10 \mathrm{mg} \text {, Citalopram } 40 \mathrm{mg} \text {, } \\
\text { Clonidine } 500 \mathrm{mg} \text {, Zopliclone } 11.25 \mathrm{mg}\end{array}$} \\
\hline 6 & OCD, Depression & \multicolumn{3}{|c|}{ Fluoxetine $20 \mathrm{mg}$} \\
\hline 7 & No comorbidities & \multicolumn{3}{|c|}{ NIL } \\
\hline 8 & OCD, Depression & \multicolumn{3}{|c|}{ Fluoxetine $40 \mathrm{mg}$, Haloperidol $2 \mathrm{mg}$} \\
\hline 9 & No comorbidities & \multicolumn{3}{|c|}{ Fluoxetine $40 \mathrm{mg}$, Risperidone $3 \mathrm{mg}$} \\
\hline 10 & $\mathrm{OCD}, \mathrm{BPD}$ & \multicolumn{3}{|c|}{$\begin{array}{l}\text { Closapine } 150 \mathrm{mg} \text {, Gabapentine } 1200 \mathrm{mg}, \\
\text { Sertraline } 200 \mathrm{mg} \text {, Clonidine } 125 \mathrm{mg}, \\
\text { Zopiclone } 15 \mathrm{mg} \text {, Topiramate } 100 \mathrm{mg}\end{array}$} \\
\hline 11 & $\begin{array}{l}\text { OCD, Anxiety, } \\
\text { Depression }\end{array}$ & \multicolumn{3}{|c|}{ Baclofen20mg, QDS,Diazepam10-30mg } \\
\hline \multicolumn{5}{|c|}{ Table 1.C DBS Parameters } \\
\hline ID & $\begin{array}{l}\text { 'randomization } \\
\text { - first condition' }\end{array}$ & Voltage (V) & $\begin{array}{c}\text { Pulse } \\
\text { Width }(\mu \mathrm{S})\end{array}$ & Frequency (Hz) \\
\hline 1 & ON & 2 & 60 & 130 \\
\hline 2 & OFF & 2.8 & 60 & 130 \\
\hline 3 & ON & 2.7 & 60 & 130 \\
\hline 4 & ON & 2.2 & 60 & 130 \\
\hline 5 & OFF & 4 & 60 & 130 \\
\hline 6 & OFF & 2.6 & 60 & 125 \\
\hline 7 & ON & 2.4 & 60 & 130 \\
\hline 8 & ON & 1.5 & 60 & 130 \\
\hline 9 & OFF & 0.8 & 60 & 130 \\
\hline 10 & OFF & 3 & 60 & 130 \\
\hline 11 & ON & 2.5 & 60 & 130 \\
\hline
\end{tabular}

\section{Methods}

\section{Patients}

Eleven patients $(9$ male, mean age $=34.3)$ with severe Tourette syndrome $(\mathrm{TS})$ were recruited from two clinics for tertiary movement disorders in the UK (UCL Queen Square Institute of Neurology, London and Salford Royal NHS Foundation Trust, Manchester). Inclusion criteria: 1) adults with stable TS; chronic tic disorder with severe functional impairment on the Yale Global 
Tic Severity Scale (YGTSS); 2) had failed conventional medical treatment at therapeutic doses of three classes of medication; behavioural intervention had been considered inappropriate or had been unsuccessful; 3) had optimized treatment of co-morbid conditions for at least 6 months; 4) were compliant with any psychosocial interventions and with surgical treatment plans. Table 1 shows the demographic and clinical details of each of the 11 patients, including the Yale Global Tic Severity Scale (YGTSS), comorbidities and medications at baseline as well as the deep brain stimulation (DBS) parameters.

\section{Experimental Design}

This study followed a double-blind, crossover, sham stimulation controlled design, according to which patients were randomly assigned to 'stimulation ON' first or 'stimulation OFF'/Sham first for a 3-month period followed by a switch to the opposite condition for a further 3 months.

Surgery procedure and stimulation programming

All 11 patients underwent implantation of bilateral DBS electrodes (3387 or 3389 Medtronic, Minneapolis, MN) in the anteromedial GPi (GPiam) under general anaesthesia. Details of neurosurgical procedures have been previously described [13]. Stimulation was initiated 6 weeks after surgery, and parameters were adjusted during a one-week un-blinded period. The optimal settings were determined by using the most effective parameters on tics with the lowest energy, without causing side effects. DBS amplitude (Volts), pulse width $(\mu \mathrm{sec})$ and frequency $(\mathrm{Hz})$ of active contacts are shown for each case in Table 1C.

\section{Neuropsychological assessment}

Patients underwent preoperative neuropsychological assessment (within 4 weeks prior to surgery) and at the end of each of the three-month blinded periods, ON and OFF DBS. The assessment was performed over a single morning session lasting 3-4 hours on average including breaks, by a trained neuropsychologist blinded to the patient's stimulation status. Patients were on their contemporary medications (see Table 1B). 
For a baseline estimate of patients' intellectual ability The National Adult Reading Test (NART, [14]) was used as a measure of premorbid intelligence quotient (IQ), and the vocabulary and matrix reasoning subtests of The Wechsler Abbreviated Scale of Intelligence (WASI,[15]) were administered to obtain an estimate of current IQ.

Memory:

The California Verbal Learning Test-II (CLVT-II,[16]) was used to assess episodic verbal memory for words and tests of non verbal memory included the Short Recognition Memory for Faces (SRMF, [17]) and the Corsi block [18].

CLVT-II involves the presentations of 16 words belonging to 4 semantic categories, over five learning trials and then short and long delayed free and cued recall and delayed recognition are tested. In the SRMF participants are shown a series of 25 faces which they classify as pleasant or unpleasant and thereafter are asked to identify, out of a pair, the face presented before. The total number of faces correctly recognized is recorded.

\section{Executive Functions:}

Executive functioning was assessed by adopting three tests from The Delis-Kaplan Executive Function System battery (D-KEFS, [19]). Trail Making Test (TMT), Verbal Fluency Test (VF) and Colour-Word Interference Test (STROOP) were administered to assess behavioral regulation, switching and cognitive flexibility and inhibition. The ability to inhibit a prepotent response was further measured by the Hayling Sentence Completion test [20].

\section{Attention:}

The Paced Auditory Serial Addition Test (PASAT, [21]), is a test of sustained attention and working memory. Participants are presented with a series of single digit numbers between 1 and 9 every 4 seconds and are instructed to add each number to the preceding one and say the sum out loud. The percentage of errors out of 30 possible responses was computed, with higher scores indicating greater impairment. The Number and letters test, one of the tests comprising the Neuropsychological Assessment Battery (NAB, [22]) was administered to measure different aspects of attention such as sustained, selective, divided attention and psychomotor speed. The four subtests involve 
timed letter cancellation, counting, serial addition, and concurrent letter cancellation and serial addition; with both accuracy and speed considered in calculating the efficiency scores.

\section{Statistical Analysis}

All analyses were conducted using the Statistical Package for the Social Sciences (SPSS version 21.0, Armonk, NY, USA). Friedman test, a non-parametric repeated measures ANOVA, was used to evaluate differences in performance between pre-operative and post-operative $\mathrm{ON}$-and OFF stimulation blinded time points. Post-hoc comparisons were performed using Wilcoxon signed rank. A Bonferroni correction was applied to control for multiple comparisons. Hence, for posthoc analysis the critical level of significance was set at 0.0167 .

\section{Results}

All 11 patients completed both blinded assessments including the full cognitive battery during cross-over periods. Patients had a pre-operative mean tic severity score of 87 (SD 9.73) and postoperative score of 74 (SD 19.3) as assessed by YGTSS. On the NART the mean pre-morbid IQ was 103.3 (SD 10.7, range 89-122), and the mean current IQ was 107.7 (SD 6.6, range 99-118), both in the average range.

\section{Effect of DBS Surgery on Cognitive Measures}

Table 2 provides the median, minimum and maximum values of group performance during the 3 cognitive assessments, at baseline, following GPiam-DBS OFF- and ON- stimulation.

A significant change relative to baseline in verbal episodic memory was observed with the majority of the CVTL-II measures showing an improvement post-operatively. Pair-wise comparisons demonstrated a significantly better performance following surgery during the OFF-stimulation condition compared to baseline in immediate recall $(\mathrm{z}=-2.8 \mathrm{p}=0.005)$, short-delay free recall $(\mathrm{z}=$ - 2.7, $\mathrm{p}=0.007)$ and long-delay cued recall $(\mathrm{z}=-2.7, \mathrm{p}=0.007)$. There was also a significant difference on TMT number sequencing and number-letter switching, with participants performing better during the OFF-stimulation condition in comparison to baseline (respectively, $\mathrm{z}=-2.6, \mathrm{p}<0.01$ and $\mathrm{z}=-2.4 \mathrm{p}<0.016$ ). The differences between the DBS ON and OFF conditions were not significant at the Bonferroni corrected $\mathrm{p}<0.0167$ for any of the measures. No other significant differences 
were identified in the patients' performance between baseline and either ON or OFF GPiam-DBS assessment on any of the other tests.

To determine if the difference between pre-operative baseline scores and OFF condition was statistically reliable, we calculated the reliable change index (RCI). The formula for calculating it is: $\mathrm{RCI}=\mathrm{X} 2$ - X1/Sdiff (follow- up score - baseline score/ the standard error of difference) (see Jacobson [23](1991). The results are then grouped into three categories showing the percentage of: improvement, decline, or no change. RCI for CLVT-II immediate recall suggests improvement in $64 \%$ in OFF condition relative to baseline, and no change in $36 \%$ of patients. RCI for CLVT-II short and long delay free recall shows that $54 \%$ of patients had improved and $46 \%$ had no change in OFF condition relative to baseline. RCI for TMT number letter switching indicates improvement in $50 \%$, and no reliable change in $50 \%$ of patients. For TMT number sequencing, RCI indicates that most of participants $70 \%$ had no change, and only $30 \%$ had improved. Thus based on the RCI, only the improvement of immediate, short and long delay free recall on the CVLT-II and the number letter switching on the TMT on the OFF condition relative to baseline were reliable. For all cognitive tests none of the patients showed a dramatic decline nor increase in performance.

Table 2: Median, minimun and maximum scores for measures of cognitive function at baseline, and with GPiam-DBS OFF and ON conditions.

\begin{tabular}{cccccccc}
\hline $\begin{array}{c}\text { Cognitive Outcome } \\
\text { (score range) }\end{array}$ & Baseline & $\begin{array}{c}\text { Blinded } \\
\text { OFF }\end{array}$ & $\begin{array}{c}\text { Blinded } \\
\text { ON }\end{array}$ & $\begin{array}{c}\text { ANOVA } \\
\text { p-value }\end{array}$ & $\begin{array}{c}\text { Post-hoc } \\
\text { OFF vs }\end{array}$ & $\begin{array}{c}\text { Post-hoc } \\
\text { Baseline vs }\end{array}$ & $\begin{array}{c}\text { Post-hoc } \\
\text { Baseline }\end{array}$ \\
& & & & & ON & OFF & vs ON \\
& & & & p-value & p-value & $p$-value \\
\hline
\end{tabular}

MEMORY

CVLT-II scaled scores

$\begin{array}{lccccccc}\begin{array}{l}\text { Trial 1 } \\ (0-16)\end{array} & 7(4-8) & 8(6-12) & 7(5-9) & 0.008^{*} & 0.020 & 0.005 * * & 0.468 \\ \begin{array}{l}\text { Trial 1-5 } \\ (0-80)\end{array} & 56(43-63) & 58(46-74) & 57(40-70) & 0.032^{*} & 0.068 & 0.018 & 0.594 \\ \begin{array}{l}\text { Short delay-free recall } \\ (0-16)\end{array} & 11(7-15) & 12(9-16) & 11(0-16) & 0.006^{*} & 0.027 & 0.007 * * & 0.675\end{array}$




\begin{tabular}{|c|c|c|c|c|c|c|c|}
\hline $\begin{array}{l}\text { Short delay-cued recall } \\
(0-16)\end{array}$ & $11(3-15)$ & $13(10-16)$ & $12(2-16)$ & $0.046 *$ & 0.084 & 0.023 & 0.341 \\
\hline $\begin{array}{l}\text { Long delay-free recall } \\
(0-16)\end{array}$ & $11(8-15)$ & $12(9-16)$ & $12(5-16)$ & 0.139 & & & \\
\hline $\begin{array}{l}\text { Long delay-cued recall } \\
(0-16)\end{array}$ & $11(6-15)$ & $13(9-16)$ & $12(1-16)$ & $0.038 *$ & 0.476 & $0.007 * *$ & 0.238 \\
\hline $\begin{array}{l}\text { Recognition-hits } \\
(0-16)\end{array}$ & $15(12-16)$ & $15(14-16)$ & $16(14-16)$ & 0.215 & & & \\
\hline $\begin{array}{l}\text { Recognition-false posi- } \\
\text { tives } \\
(0-16)\end{array}$ & $1(0-7)$ & $1(0-14)$ & $1(0-7)$ & 0.542 & & & \\
\hline $\begin{array}{l}\text { SRMF } \\
(0-25)\end{array}$ & $24(22-25)$ & $25(19-25)$ & $25(23-25)$ & 0.214 & & & \\
\hline $\begin{array}{l}\text { CORSI BLOCKS } \\
(0-16)\end{array}$ & $7(5-10)$ & $7(6-10)$ & $8(5-11)$ & 0.964 & & & \\
\hline \multicolumn{8}{|c|}{ EXECUTIVE FUNCTIONS } \\
\hline \multicolumn{8}{|c|}{ Trail Making Test scaled scores } \\
\hline Visual Scanning & $11(3-14)$ & $10(5-13)$ & $11(1-14)$ & 0.472 & & & \\
\hline Number Sequencing & $10(4-13)$ & $13(8-14)$ & $10(6-13)$ & $0.025 *$ & 0.093 & $0.010 * *$ & 0.572 \\
\hline Letter Sequencing & $11(1-13)$ & $11(8-13)$ & $12(5-14)$ & 0.114 & & & \\
\hline $\begin{array}{l}\text { Number-Letter Switch- } \\
\text { ing }\end{array}$ & $10(2-12)$ & $11(7-14)$ & $10(8-13)$ & $0.015 *$ & 0.098 & $0.016 * *$ & 0.493 \\
\hline Motor speed & $12(4-13)$ & $13(7-14)$ & $12(7-14)$ & 0.321 & & & \\
\hline \multicolumn{8}{|c|}{ Verbal Fluency scaled scores } \\
\hline Letter fluency & $12(6-18)$ & $14(7-16)$ & $13(6-18)$ & 0.723 & & & \\
\hline Category & $10(5-16)$ & $10(6-14)$ & $9(4-14)$ & 0.293 & & & \\
\hline Category switching & $12(5-19)$ & $11(8-18)$ & $11(6-14)$ & 0.741 & & & \\
\hline \multicolumn{8}{|c|}{ Stroop Colour-word interference test scaled scores } \\
\hline Colour naming & $9(4-13)$ & $11(7-13)$ & $10(2-12)$ & 0.245 & & & \\
\hline Word reading & $11(5-12)$ & $11(7-14)$ & $10(5-13)$ & 0.975 & & & \\
\hline Inhibition & $10(2-14)$ & $10(7-15)$ & $11(4-14)$ & 0.239 & & & \\
\hline Inhibition/switching & $10(5-13)$ & $10(5-14)$ & $9(2-14)$ & 0.614 & & & \\
\hline
\end{tabular}




$\begin{array}{lcccc}\text { Section A } & 4.5(3-6) & 6(3-6) & 6(4-6) & 0.174 \\ \text { Section B } & 6(4-6) & 6(4-6) & 6(5-6) & 0.368 \\ \begin{array}{l}\text { Section B } \\ \text { Combined Error Score }\end{array} & 7(2-8) & 7(6-8) & 7(6-8) & 0.670\end{array}$

\begin{tabular}{|c|c|c|c|c|}
\hline \multicolumn{5}{|l|}{ ATTENTION } \\
\hline PASAT (\% errors) & $12(5-25)$ & $10(0-18)$ & $13(7-18)$ & 0.497 \\
\hline \multicolumn{5}{|c|}{ NAB Numbers and Letters Efficiency raw scores } \\
\hline $\begin{array}{l}\text { Part A } \\
(\max 200)\end{array}$ & $\begin{array}{c}98(59- \\
112)\end{array}$ & $\begin{array}{c}101(72- \\
115)\end{array}$ & $\begin{array}{c}94(73- \\
133)\end{array}$ & 0.301 \\
\hline $\begin{array}{l}\text { Part B } \\
(\max 200)\end{array}$ & $\begin{array}{c}74(57- \\
103)\end{array}$ & $71(64-119)$ & $\begin{array}{c}75(40- \\
133)\end{array}$ & 0.641 \\
\hline $\begin{array}{l}\text { Part C } \\
(\max 200)\end{array}$ & $54(35-84)$ & $48(27-81)$ & $52(38-91)$ & 0.459 \\
\hline $\begin{array}{l}\text { Part D } \\
(\max 200)\end{array}$ & $43(28-70)$ & $47(40-66)$ & $43(32-59)$ & 0.097 \\
\hline
\end{tabular}

\section{Discussion}

Bilateral DBS of the limbic part of the GPi (GPiam) has been shown to reduce motor and vocal tics in two randomized double-blind controlled trials [12], [13]. In the study performed by our group 13 patients completed the trial and showed a 15\% decrease in tic severity during the crossover randomized double-blind phase and a $40 \%$ reduction during the open-label phase. In the largest randomized controlled DBS trial of patients with TS, Welter and colleagues assessed the efficacy of GPiam-DBS and reported some amelioration of tic severity in the open label phase. Both studies used as a primary outcome the YGTSS that measures a patient's manifestation and severity of tics.

The impact of GPiam-DBS on cognitive function was examined in the current study. Our results show no major significant change in cognition following bilateral GPiam-DBS providing support for its cognitive safety. Other than post-operative improvement of performance on verbal episodic memory on the CVLT-II and executive function on the Trail-making test in OFF-DBS relative to baseline, we found no significant change on any of the measures of cognitive function including measures of verbal fluency, Stroop test and attention. By contrast, other studies have reported that 
thalamic Cm-Pf DBS in severe TS was associated with decline of executive functions measured by the Stroop and verbal fluency tests [24].

For some tests the patients' performance was better during the OFF-DBS compared to pre-operative baseline. Specifically, we found better performance on TMT number-letter switching a measure of behavioural regulation, cognitive flexibility and processing speed and CVLT-II verbal memory immediate recall and short-delay free recall after surgery with GPiam-DBS OFF relative to the pre-operative baseline assessment. It is difficult to explain the small improvements relative to baseline assessment in the DBS OFF condition. They do not reflect stimulation effects, as none of the DBS OFF vs DBS ON differences were significant. If they were simply due to a surgical lesion effect, then they would be expected to be also present in the DBS ON condition, which was not the case. Most of the patients had comorbidities, and it is possible that alterations of these may have contributed to the observed effects. The numbers are too small to allow comparisons. The major limitations of this study are the small sample size and the short follow-up duration. Long term follow-up of the patients and further comparison of the DBS ON and OFF states may clarify these results.

We did not observe any change on the Hayling sentence completion task which requires volitional initiation and inhibition of prepotent verbal responses or the Stroop inhibition subtest after GPiam DBS surgery. A previous study showed that episodic memory, working memory and flexibility, remained stable after bilateral implantation in the ventromedial part of the GPi and the CM-P DBS (Welter 2007 [25]). The present study extends these previous findings providing data about the lack of negative impact of GPiam-DBS on a more extensive neuropsychological battery of cognitive tests including memory, executive function, verbal fluency, psychomotor speed, sustained attention, selective attention and divided attention.

\section{Reference:}

[1] A. P. Association, Diagnostic and statistical manual of mental disorders (DSM-5®). American Psychiatric Pub, 2013. 
[2] J. Jankovic, “Tourette's Syndrome,” N. Engl. J. Med., vol. 345, no. 16, pp. 1184-1192, Oct. 2001.

[3] A. E. Cavanna et al., "Health-related quality of life in Gilles de la Tourette syndrome: a decade of research," Behav. Neurol., vol. 27, no. 1, pp. 83-93, 2013.

[4] J. W. Mink, "Neurobiology of basal ganglia and Tourette syndrome: basal ganglia circuits and thalamocortical outputs," Adv. Neurol.-N. Y.-RAVEN Press., vol. 99, p. 89, 2006.

[5] M. Jahanshahi, I. Obeso, J. C. Rothwell, and J. A. Obeso, "A fronto-striato-subthalamicpallidal network for goal-directed and habitual inhibition," Nat. Rev. Neurosci., vol. 16, no. 12, p. 719, 2015.

[6] D. Martino and T. Hedderly, "Tics and stereotypies: A comparative clinical review," Parkinsonism Relat. Disord., vol. 59, pp. 117-124, Feb. 2019.

[7] M. M. Robertson et al., "Gilles de la Tourette syndrome," Nat. Rev. Dis. Primer, vol. 3, p. 16097, 2017.

[8] D. Martinez-Ramirez et al., "Efficacy and safety of deep brain stimulation in Tourette syndrome: the international Tourette syndrome deep brain stimulation public database and registry," JAMA Neurol., vol. 75, no. 3, pp. 353-359, 2018.

[9] S. Pandey and D. Dash, "Progress in Pharmacological and Surgical Management of Tourette Syndrome and Other Chronic Tic Disorders:," The Neurologist, vol. 24, no. 3, pp. 93108, May 2019.

[10] V. Vandewalle, C. van der Linden, H. J. Groenewegen, and J. Caemaert, "Stereotactic treatment of Gilles de la Tourette syndrome by high frequency stimulation of thalamus," The Lancet, vol. 353, no. 9154, p. 724, 1999.

[11] I. Neuner, K. Podoll, D. Lenartz, V. Sturm, and F. Schneider, "Deep brain stimulation in the nucleus accumbens for intractable Tourette's syndrome: follow-up report of 36 months," Biol. Psychiatry, vol. 65, no. 4, pp. e5-e6, 2009.

[12] M.-L. Welter et al., "Anterior pallidal deep brain stimulation for Tourette's syndrome: a randomised, double-blind, controlled trial," Lancet Neurol., vol. 16, no. 8, pp. 610-619, 2017.

[13] Z. Kefalopoulou et al., "Bilateral globus pallidus stimulation for severe Tourette's syndrome: a double-blind, randomised crossover trial," Lancet Neurol., vol. 14, no. 6, pp. 595605, 2015.

[14] H. E. Nelson and J. Willison, National adult reading test (NART). Nfer-Nelson Windsor, 1991.

[15] D. Wechsler, WASI-II: Wechsler abbreviated scale of intelligence. PsychCorp, 2011.

[16] D. C. Delis, CVLT-II: California verbal learning test: adult version. Psychological Corporation, 2000.

[17] E. K. Warrington, The Camden memory tests manual, vol. 1. Psychology Press, 1996.

[18] P. M. Corsi, "Human memory and the medial temporal region of the brain.," PhD Thesis, ProQuest Information \& Learning, 1973.

[19] D. C. Delis, E. Kaplan, and J. H. Kramer, Delis-Kaplan Executive Function System $(D-$ KEFS®): Examiner's Manual: Flexibility of Thinking, Concept Formation, Problem Solving, Planning, Creativity, Impluse Control, Inhibition. Pearson, 2001.

[20] P. W. Burgess and T. Shallice, "The hayling and brixton tests," 1997.

[21] D. M. A. Gronwall, "Paced auditory serial-addition task: a measure of recovery from concussion,” Percept. Mot. Skills, vol. 44, no. 2, pp. 367-373, 1977. 
[22] R. A. Stern and T. White, NAB, Neuropsychological Assessment Battery: Administration, scoring, and interpretation manual. Psychological Assessment Resources Lutz (FL), 2003.

[23] Jacobson NS and Truax P., "Clinical significance: A statistical approach to defining meaningful change in psy- chotherapy research.," J Consult Clin Psychol, vol. 59, pp. 12-19, 1991.

[24] A. Y. Smeets et al., "Thalamic Deep Brain Stimulation for Refractory Tourette Syndrome: Clinical Evidence for Increasing Disbalance of Therapeutic Effects and Side Effects at Long-Term Follow-Up," Neuromodulation Technol. Neural Interface, vol. 21, no. 2, pp. 197-202, 2018.

[25] M.-L. Welter et al., "Internal pallidal and thalamic stimulation in patients with Tourette syndrome," Arch. Neurol., vol. 65, no. 7, pp. 952-957, 2008.

\section{AUTHOR ROLES:}

Research project: A. Conception, B. Organization, C. Execution; 2. Statistical Analysis: A. Design, B. Execution, C. Review and Critique; 3. Manuscript Preparation: A. Writing of the first draft, B. Review and Critique

D.C. : $1 \mathrm{C}, 2 \mathrm{C}, 3 \mathrm{~A}, 3 \mathrm{~B}$

M.B. : 1C, 2B, 3B

Z.K. : 3B

L.Z. : 3B

J.C. : 3B

C.M. : 3B

H.A. : 3B

V.D. : 3B

J.H. : 3B

L.K.I. : 3B 
M.S. :1B, 3B

J.E. : 1B, 3B

P.L. :1B, 3B

M.H. : 1A, 3B

E.J. : 3B

T.F. :1A, 3B

M.J. :1A, 1B, 2A, 2C, 3B

Full financial disclosure for the previous 12 months

The authors report no disclosures. 
